\title{
Gd-Ge (Gadolinium-Germanium)
}

\section{H. Okamoto}

The Gd-Ge phase diagram in [Massalski2] was redrawn from [1989Gok]. This phase diagram was constructed based primarily on [1980Ere]. The $\mathrm{Gd}_{3} \mathrm{Ge}_{5}$ phase was a single phase in [1980Ere], but [1989Gok] considered it to be dimorphic with the transition temperature below $600{ }^{\circ} \mathrm{C}$ based on crystallographic data reported in the literature.

Figure 1 shows the Gd-Ge phase diagram calculated by [2008Che]. The phase boundary data of [1980Ere] were used in the thermodynamic modeling. Accordingly, the diagrams of [1989Gok] and [2008Che] are similar. The most significant difference is related to the homogeneity range of polymorphic $\mathrm{Gd}_{2} \mathrm{Ge}_{3}$ and $\mathrm{Gd}_{3} \mathrm{Ge}_{5}$ phases. In [1989Gok], these phases were shown with a constant width over a wide temperature range $\left(\sim 2\right.$ at. $\%, 0$ to $1200{ }^{\circ} \mathrm{C}$ for $\mathrm{Gd}_{2} \mathrm{Ge}_{3}$ ). Because this feature is unlikely, the line compounds shown in Fig. 1 are more plausible. However, the absence of measurable width for these compounds must be confirmed.

\section{References}

1980Ere: V.N. Eremenko, B.G. Batalin, Yu.I. Buyanov, and I.M. Obushenko, Constitution Diagram of the Gadolinium-Germanium System. Poroshk. Metall., 1980, 2, p 40-45, in Russian: Sov. Powder Metall. Met. Ceram., 1980, 19, p 104-108

1989Gok: A.B. Gokhale, G.J. Abbaschian, The Gd-Ge (Gadolinium-Germanium) System. Bull. Alloy Phase Diagrams, 1989, 10(2), p 147-152

2008Che: H.L. Chen, Y. Du, C.Y. He, Thermodynamic Modeling of the Gadolinium-Germanium System. J. Alloys Compd., 2008, 462, p 181-186

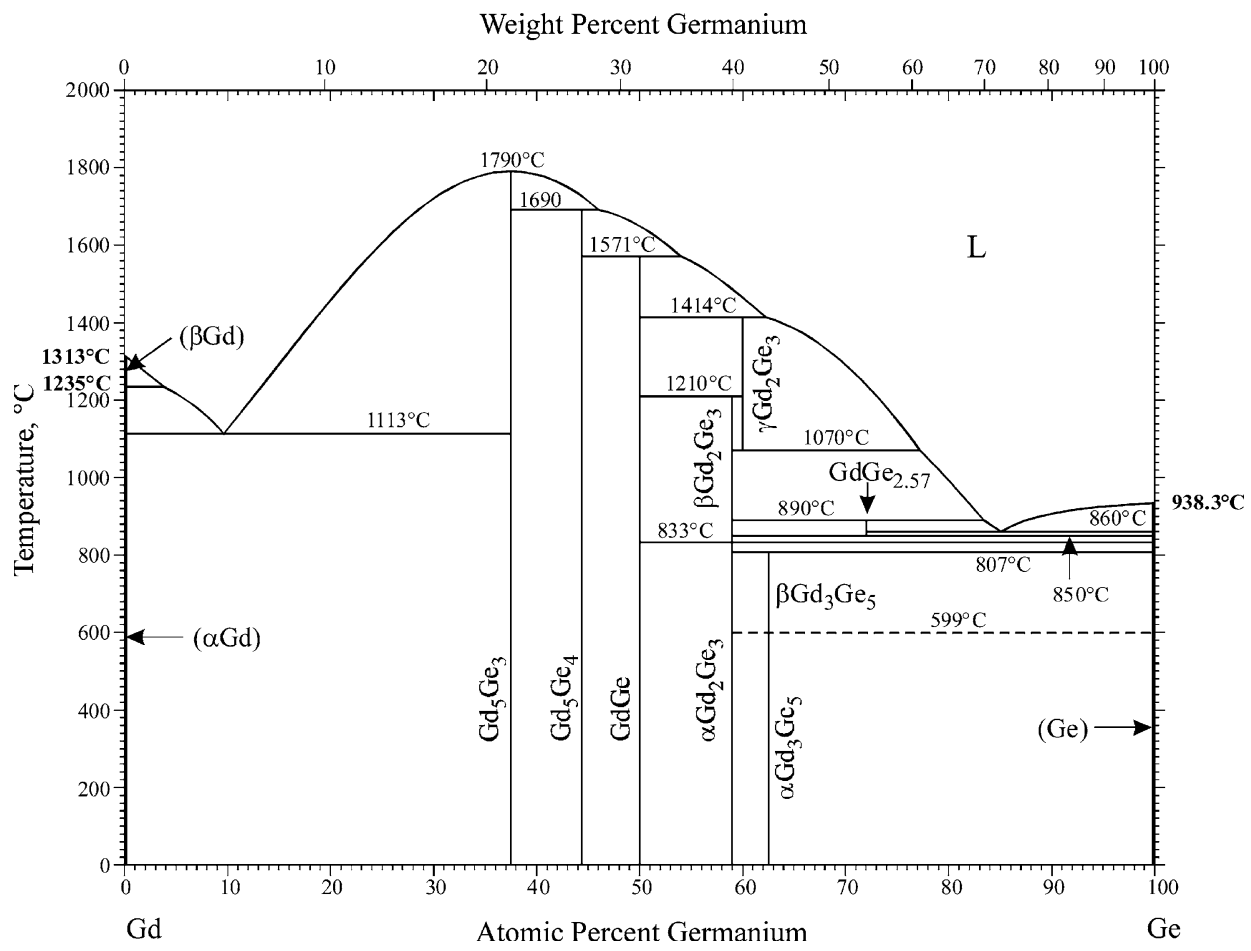

Fig. 1 Gd-Ge phase diagram 